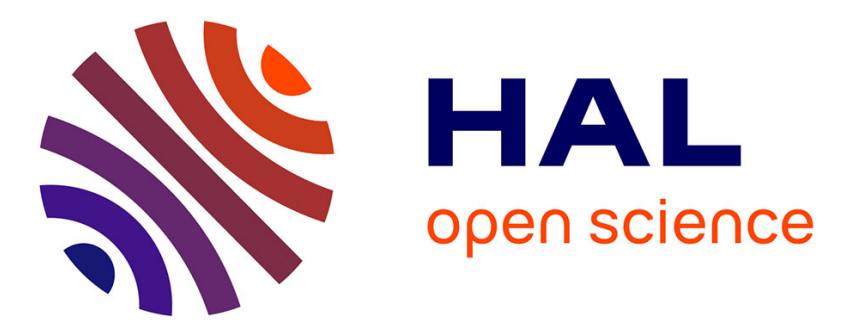

\title{
A nonlinear Bayesian model of trait selection forces
}

\author{
Rune Østergaard Pedersen, Anne Bonis, Christian Damgaard
}

\section{To cite this version:}

Rune Østergaard Pedersen, Anne Bonis, Christian Damgaard. A nonlinear Bayesian model of trait selection forces. Ecological Modelling, 2019, 393, pp.107-119. 10.1016/j.ecolmodel.2018.12.002 . hal02991038

\section{HAL Id: hal-02991038 \\ https://hal.science/hal-02991038}

Submitted on 6 Nov 2020

HAL is a multi-disciplinary open access archive for the deposit and dissemination of scientific research documents, whether they are published or not. The documents may come from teaching and research institutions in France or abroad, or from public or private research centers.
L'archive ouverte pluridisciplinaire HAL, est destinée au dépôt et à la diffusion de documents scientifiques de niveau recherche, publiés ou non, émanant des établissements d'enseignement et de recherche français ou étrangers, des laboratoires publics ou privés. 


\title{
Running headline: Trait selection forces
}

\section{Title}

\section{A Nonlinear Bayesian model of trait selection forces}

By Rune $\varnothing$ stergaard Pedersen ${ }^{\mathrm{a}}$, Anne Bonis $^{\mathrm{b}}$ and Christian Damgaard ${ }^{\mathrm{c}}$

${ }^{a}$ Aarhus University, Vejlsøvej 25, 8600 Silkeborg, Denmark, E-mail address: rupd@bios.au.dk

b UMR 6042 GEOLAB, CNRS - University Clermont Auvergne, Clermont-Ferrand, France

${ }^{c}$ Aarhus University, Vejlsøvej 25, 8600 Silkeborg, Denmark, E-mail address: cfd@bios.au.dk

\begin{abstract}
We model trait selection by deriving and comparing models for direct trait selection and selection that is mediated by interspecific interactions. The purpose is to model the two selection forces simultaneously, in order to account for potential trait covariance in the estimation procedure when including multiple trait values. In addition, we identify those traits most important for selection forces, and the role of flooding duration. A Bayesian modelling approach is applied and fitted to plant species cover including stochastic variable selection, to test the importance of individual traits on selection forces. We used pin-point data from wet grasslands of the French Atlantic Coast. Our results show that trait selection forces are driven by direct selection and, to a minor extent, by selection mediated by interspecific interactions. Of the tested traits leaf dry matter content (LDMC) and specific leaf area (SLA), seemed most important for selection forces. We find a significant effect of flooding on selection forces. Parameter covariance analysis revealed flooding to be most strongly correlated with direct selection forces. The method has less critical assumptions regarding the geographical limit of the ecological environment than a traditional filtering approach, and allows weighting traits simultaneously and accounting for their covariance. Inference is easy to obtain from the posterior parameter distributions of the Bayesian estimation. Thus, the Bayesian method presented is very objective. A program architecture is supplied in the R-programming language.
\end{abstract}


Keywords: Bayesian model, interspecific competition, multiple traits, plant cover, selection forces 
Local species assemblages made off local communities results from the selection of the regional species pool by various filters.

4 Lortie et al. (2004) describes three filters, going from the coarse to the fine scale. The first filter is a

5 spatial/geographical filter, which provides a boundary limiting the spread of the species, for example the

6 sea or a mountain chain. The second level is a physiological filter, caused by environemental conditions

7 filtered plant species according to their respective tolerance. Finally, the biotic filter works by plant-plant

8 interaction by competition, symbiosis and facilitation. In praxis, all three levels must interact to some

9 extent, and also vary with a stochastic component, physiological and biotic filters interacted(Shipley (2010)

11 . For example, a drought intolerant plant will also compete less in a dry environment, whereas less intuitive pattern of biotic interaction issues have also been find along elevation gradient (see e.g. Damgaard et al 2017, Oecologia. A Any modeling aiming to predict plant abundance pattern in environmental gradient within their community must thus include both filters, and their effect at the adequate spatial scales. Functional traits (Garnier et al., 2016) is a way to quantify the adaptative species'response to constraint , from plant community to larger levels of organization, i.e. across environmental gradients. At the same time knowing the species composition on the community level they may be applied in models of spatial interaction on the finest scale by traits. Thus, traits in models can work on different spatial resolutions. In ecology, traits can be defined as measures of expected genetic heritable abilities of different species or performance under idealized conditions having no restrains (McGill and Brown, 2007). Most often, the traits refer to a pool of individuals in the environment rather than a single subject (Violle et al., 2007). Traits are often applied in the study of selection forces of plant populations in a two-step process. Firstly, through a survey the species of a habitat are identified, and, secondly, the distributional properties of their traits are studied as a proxy for the filtering (pass through) facilitated by selection forces (Keddy, 1992, 
Loranger et al. 2016). This is done by comparing observed trait pattern with a global species trait distributional reference. If the variance of the local environment is less than expected by random sampling in a null model (Bernard-Verdier et al., 2012), trait values are driven in a direction towards a common stable equilibrium. If the variance is higher than at random, then the traits are selected in divergent directions. The outcome of such a method depends on specification of the global trait pool and the geographical area under investigation, the first of which it is critical to define properly because it serves as an ecological reference model (Gotelli and Graves, 1996). The temporal stage of the area is also important, since pioneering species will perform differently in different stages of succession. If the subjective definition of the null model is biased relative to the "correct" one, then all successive results are influenced. In addition, it can be difficult to distinguish which part of selection is due to niche partitioning and which is due to interspecific competition (Adler et al., 2013), since both can result in the same trait distribution. Another weakness of modelling each trait separately is that it neglects trait interaction and studies selection forces of traits independently of each other. However, since traits are in fact multivariate measures of potential plant performance, it seems reasonable to assume that they simultaneously will have an impact on the outcome of the selection process (Garnier et al., 2016, P. 11 and 20). Studies using traits often look at species diversity and its relation to trait variation (Dwyer and Laughlin, 2017). Because trait variation and species richness seem not to be related in a simple linear way, covariance among trait, i.e. the fact that traits express the same property or interact in a synergistic way, becomes important. Therefore, new methods are required that look at traits simultaneously and integrate them in the selection process. Traits are often surrogates, and initial exclusion of traits can be made e.g. by principal components analysis (Bernard-Verdier et al., 2012; Johnson and Wichern, 2007), to reduce the number of model variables and make parameter estimation easier. While a principal components analysis is an objective measure of correlation, data variables need to be seen in a framework where the outcome of species competition interaction is also included and confounding effects can be studied. Lavorel and Garnier (2002) underline this point by differentiating traits that are causes/drivers of the pattern that we observe in nature (effect 
traits) or merely a phenotype resulting from a response to affect and stress induced to the environments (response traits).

As pointed out by Mather (1953), the selection forces may be divided into three possible outcomes: directional, disruptive and stabilizing selection. If we assume that the original quantity of interest - for example height of individuals over an area, is symmetrically distributed around a mean, then stabilizing selection will result in the same mean, but less variance, i.e. the heights will become less dispersed. Directional selection, on the other hand, will shift both the mean, but also the frequency in form of skewness. The reason for this is that selection forces act differently on the extreme values of the initial distribution. Disruptive selection tends to multimodality of the resulting distribution, i.e. more new optima. Any model of selection forces must capture these theoretical outcomes.

For this purpose, Damgaard (2016) presented a method based on theoretical justifications and assumptions about the competitive processes using nonlinear models. These models make it possible to:

1) Decide which of the three types of fundamental selection forces described by Mather that are supported by the data.

2) Differentiate between the direct selection forces originating from traits alone and selection that is mediated by interspecific interactions.

We make the first practical implementation of the method of Damgaard in order to study the empirical process of trait selection. The models of Damgaard are essentially modifier functions made according to our expectation on different types of directional selection. In addition, a term involving species interaction is applied. The general form of the model is:

Equation 1

$$
q^{\prime}=q * F * C
$$

Where $q^{\prime}$ is the quantitative outcome of selection forces collected in a survey, e.g. observed cover, and $q$ is the cover in the previous year. $F$ is the expression of the direct trait selection forces, and $C$ is an expression 
of selection that is mediated by interspecific interactions. We give different examples of modifier functions and put them into the context of the selection forces. Adler et al. (2013) advocate that any model of competition should include spatial as well as temporal variation in the environment and its resources in order to incorporate the carrying capacity of the plant species (niche differentiation) and competitive pressure caused by the spatial pattern (Wyszomirski and Weiner, 2009). We therefore model the spatial scale at two levels, firstly at a landscape level with a flooding gradient in order to include the effect of hydrology on species interaction and the impact of change in the species ecological and physical amplitude (Bernard-Verdier et al., 2012). This is a proxy variable for the realized and fundamental niche (Harper, 1977). Secondly, we model at a plot level where species interactions could be present. Hence, we include both niche differentiation and competitive effects. The mathematical formulation is important for the spatial incorporation of spatial effect, and this is done by means of the $F * C$ terms, which will be described more in detail later. We apply a Bayesian framework, as it allows for inference of the model parameters using their posterior distribution without dubious assumptions or mathematical approximations of the joint distribution of model parameters (Montgomery et al., 2006, p. 546).

The objectives of the study are:

a) To develop and fit a model of the selection forces in a natural environment, which include space, time and multiple traits.

b) To test whether direct selection forces and selection that is mediated by interspecific interactions are important for species abundance.

c) To see whether hydrology has an impact on the selection forces. 


\section{Sampling design}

The data was collected using the pin-point method, where a frame $25 * 25 \mathrm{~cm}$ contain points positioned along the diagonal of the frame located with $4 \mathrm{~cm}$ apart yielding 17 pin-points per frame for 70 plots. At each point, a needle was positioned vertically towards the ground and a plant species was recorded, if it touched the needle. The fraction of the plant relative to all recorded species in the grid could then be calculated and applied as plant cover $(q)$.

Measurements in the first period took place from 23-29 October 2008 and in the second period from 19-20 October 2009. We made the assumption that plot cover of species between the years could be regarded as paired observations, despite the fact that it was not measured exactly at the same time of the year. This has previously been tested using the data in the current study and has proven to be a valid approach (Damgaard et al., 2016).

\section{Study area and data}

The data was collected in the Marais poitevin marshland on the French Atlantic coast $\left(46^{\circ} 26 \mathrm{~N}, 1^{\circ} 13 \mathrm{~W}\right)$. The marshland is grazed by cattle and horse, and the plots were fenced to prevent grazing doing the study period. The plant community is dominated by different grass species, mainly Agrostis Stolonifera (L.) (51 \% of pinpoint observations) and Cynosurus Cristatus (L.) (Around $13 \%$ ). A summary is given in Figure 1 and the right column of Table 1. The mean precipitation falls in the winter, with a surplus of $220 \mathrm{~mm}$ precipitation when accounting for evapotranspiration. The summer has a deficit of 300-350 mm (Amiaud et al., 1998). The average of the minimum*, and maximum** temperatures in the four seasons are respectively (winter $3^{*}, 9.7^{* *}$ : spring $6.3^{*}, 15^{* *}$, summer $13^{*}, 23.3^{* *}$, autum:8.7*,17**) (taken from the city La-Rochelle - France) (Climatedata.eu, 2017). Damgaard et al. (2016) gives a more detailed description of the study site. 
116 For each plot, the traits were measured and an average abundance was taken as a general estimate of trait

117 performance for each species in the data, though other methods using a probability weighted average 118 could also have been used (Bernard-Verdier et al., 2012). The trait values can be seen in Table 1. We 119 selected the species trait values specific leaf area (SLA), measured on one-side divided by its oven dry mass $120\left(\mathrm{~m}^{2} / \mathrm{kg}\right)$, leaf dry matter content (LDMC) $(\mathrm{mg} / \mathrm{g})$, calculated as the ratio between oven-dry mass of leaf divided by its water saturated mass, and vegetative height $(\mathrm{m})$, defined as distance between the top of the species and the ground.

123 These traits are considered important measures of plant fitness (Dwyer and Laughlin, 2017) on for example 124 vegetative growth (LDMC), light competition (Vegetation height), and respirational processes (SLA). For the 125 species Plantago major (L.), the LDMC was missing and set to the average during the calculations. Flooding impacts/constrains plant performance and plant interaction due to its role in the main plant's determinant process through e.g. photo synthesis, transpiration and diffusion of gases in the root system. The Sum Exceedance Value (SEV) (Swetnam et al., 1998) was applied as a proxy for flooding. It is calculated by counting the number of days during the year that the water level exceeds a threshold that causes stress due to aeration and multiplying these numbers by the difference in observed and threshold water levels, followed by summation.

132 In the grassland, the soil conductivity peaks where the flooding is of intermediate duration. Thus, though 133 SEV is a measure of aeration and water shortage, aspects regarding salinity are also incorporated. The 134 calculations of SEV was done as specified by Damgaard et al. (2016). Because we collected cover data in 135 two periods, some species only appeared in one year, indicating ingrowth or mortality. In order to utilize 136 the collected data information and avoid bias by removing species that are rare in the area, or missing due 137 to the probabilistic nature of the sampling design, we set missing cover values close to 0 and assumed SEV 138 to be constant for those observations. A motivation for including hydrology in studies of cover from the 139 French wet grasslands can be found in Damgaard et al. (2016) and Violle et al. (2011), who found strong 
significant correlations between observed species cover and hydrology in the same data. Selection may

141 therefore depend on hydrology.

\section{Model, estimation and evaluation}

A phenotype under selection may be summarized by its empirical density function. We can interpret the selection forces as functions to modify this distribution. Depending on the shape of the modifying function, the selection forces change the moments of the phenotype distribution (Harper, 1977, 758-760 ; Westoby, 1982). Also, the variance of the modifying function has an impact (Hara, 1984). For example, directional selection affects the mean and skewness of this distribution, whereas stabilizing selection will affect only the variance. Disruptive selection tends to affect both the mean and skewness. Damgaard (2016) made functions that are capable of doing this modification, and the model applied here is an extension of these methods seen in Equation 1. $F$ is a growth function for estimation of the direct selection forces originating from the $x^{\prime} t h$ trait, and $C$ an expression of the selection forces put on species with trait $x$ from competing species $y$. The idea is to separate direct selection from traits and the selection that is mediated by interspecific interactions into two, in order to model each of them individually. This allows complex models of the selection outcome. The terms $q$ and $q^{\prime}$ are the covers in Year and Year+1. Summation was done over all $\mathrm{m}$ plots, for $\mathrm{k}$ traits.

\section{Equation 2}

$$
\boldsymbol{q}_{j}^{\prime}=q_{j} \sum_{k=1}^{m}\left(F_{k}(x, S E V)\left(\sum_{y \in \Omega} C_{k}(x, y, S E V) q_{t_{k}=y}\right)\right)+\varepsilon
$$

Because $F$ and $C$ are jointly estimated in a one-step model, their interaction can be studied be means of the parameter correlations. The hydrology $(S E V)$ variable was included into each of the functions $F$ and $C$ by a an easily interpretable linear term, as shown in Table 2 . Also, the table contains all models tested in the study, with an explanation in the most left column of the table. Spatial patterns are modelled implicitly since the pin-point method is a spatial sampling procedure. Furthermore, the mathematical formulas of 
Table 2 assumes different effect nonlinear (spatial) effects of the traits. For example Model 3 of Table 2 contains the expression shown in Equation 3, where $\operatorname{Exp}$ is the natural exponential function, $H$ is a term measuring hydrology and $y$ and $x$ denotes the traits observed in the pinpoint frame. The subtraction of the traits put implicit assumptions about their spatial interaction, which cannot be proved, but justified by statistical analysis. The other models of Table 2, put other assumptions on the spatial interaction such as a fraction (Model 4). In addition $H$ was assumed to enter as a multiple, in order to separate this term from separately from the trait term, but allow potential interaction to be studied. Hydrology is modelled per plot and therefore this is also a spatial measure. Inside the pinpoint frame, we made a mean-field assumption (Bolker and Pacala, 1999), thus we do not apply the needle positions in our analysis.

\section{Equation 3}

$\left.C_{D I R_{-} k}(x, y, H)=\operatorname{Exp}(-H(y-x))\right)$

The model was estimated using the Metropolis algorithm (M) (Gelman et al., 2004, p. 289-290), a Markov chain Monte Carlo procedure (MCMC). This algorithm is simple and able to fit non-linear models. Complex interactions were analyzed by the joint model parameter distributions using Pearson correlations. In order to apply a normal distributed probability density function (PDF) logit transformations were made on $q_{j}^{\prime}$ and $q_{j}$. The $\mathrm{M}$-algorithm requires a symmetric proposal function, hence we applied this when possible, in most cases a normal distribution. Since the variance parameters cannot be negative, a normal distribution with small variance was applied and, in the rare negative case, the proposal was set close to 0 .

The priors were assumed normal distributed, except for the variance, which was gamma distributed with both scale and rate parameters equal to 2, to avoid negative values. For all models, 150.000 simulations of the M-algorithm were made. After removing 10.000 burn-in observations the remaining observations were applied to model the joint and marginal posterior distributions.

Model comparison was made using the Deviance Information Criteria (DIC) (Spiegelhalter et al., 2002; Zuur et al., 2009, p. 528) by application of the mean parameter of each marginal parameter distribution. To 
evaluate the predictive performance and account for the dispersal of the marginal distributions, i.e. their variance, we made 15.000 simple random samples in the posterior distributions of the parameters, excluding the error term of the normal density describing the dependent variable. The empirical density of cover $q_{j}^{\prime}$ was compared to the simulated cumulative empirical distribution using the Kolmogorov-Smirnof test (Massey, 1951).

One assumption, which may be critical, is the additivity of the terms in Equation 2, but this can be justified by means of variable selection, which allows selecting the terms that have parameters significantly different from zero. We applied the variable selection proposed by Kuo and Mallick (KM) (1998). In short, the method of Kuo and Mallick introduces a multiplicative indicator to each model term. The indicator variable consist of two parts, a "0" part which is assumed non-stochastic and is named the spike, and a " 1 " part (the slab) which has Bernoulli (Owen et al., 2009, 268) prior distribution. We extend Equation 2 to include the indicator $I_{1} \ldots I_{k}$ variables as in Equation 4.

\section{Equation 4}

$$
q_{j}^{\prime}=q_{j} \sum_{k=1}^{m} I_{k}\left(F_{k}(x, S E V)\left(\sum_{y \in \Omega} C_{k}(x, y, S E V) q_{t_{k}=y}\right)\right)+\varepsilon
$$

\section{The indicator variable enters the $\mathrm{M}$-algorithm, and the preferred model is the one where the posterior} inclusion probabilities of the indicator variable are higher than 0.5 , i.e. the indicator variable enters in at least $50 \%$ of the selected models, this is called the median probability model (Barbieri and Berger, 2004). To test the sensitivity of the Bernoulli distribution, we ran the selection including 30,50 and 80 percent of the variables and found, using DIC, the best results with $80 \%$ inclusion. This is due to the high number of model parameters, which seems sensitive to a sudden exclusion of a whole term, making it difficult to get acceptance in the $\mathrm{M}$-algorithm. One advantage of the $\mathrm{KM}$ method is that it runs as an integrated part of the $\mathrm{M}$-algorithm, and therefore the computation time is less than an all-possible subset test (Montgomery et al., 2006). Furthermore, contrary to the stochastic search variable selection method (SSVS) (George and 
McCulloch, 1993) the KM method allows for priors with a mean other than 0 , and no standardization of the variables is needed. In order to improve the mixing properties of the chain, the chain value of the individual parameters that were multiplied to $I_{k}$ were retained whenever each of the terms $I_{k}$ of Equation 4 was 0 . In addition, when predictions were made from the mean parameter values we used a conservative approach so that the indicator variable parameter was included in the model whenever it appeared in more than 5 pct. of the MCMC simulations, i.e. $I_{k}$ were statistically significant at the 5 percent level. A program for model estimation and evaluation was made in R ( $R$ Development Core Team, 2016), and a flowchart of the programs is available in the online Appendix A.1, which can be send on request.

\section{Results}

In Figure 1 the left side of the boxplots shows the cover for the different species in the first measurement period, and the right side is the change registered in the second. We see that many species show a change in cover bteewn the two periods, potentially due to selection forces, making further modelling attempts reasonable. Plots of SEV versus cover for different species (see Figure A. 2 in Appendix A.2) revealed strong trends and thus justify the inclusion of this variable in the model. We noticed that some species however have almost the same cover.

The chains produced by the MC-algorithm showed good mixing properties, though at least 10.000 burn-ins, were needed before the chain seemed to stabilize. Some correlations were present between the parameters, and this may be of general interest due to the biological nature of the model. The time for running the model seems limited by the term $C_{k}$ (Equation 2), which requires looping through all species on the plot level. Nevertheless, within 10 days we could compute more than $150.000 \mathrm{MCMC}$ iterations on a standard PC 2.4 GHz processor of even the slowest model tested, making the method applicable to most practical implementations. For the more complicated models (Model 4-5), we manually calculated initial guesses in order reduce the burn-in period of the MCMC. Our experience is that few model parameters set 
near to mean trait values are a good starting point. In addition, the variances of the posterior parameter histograms of Models $4-5$ seemed smaller, probably due to the formula using exponential in fractions, making only a narrow number of values reasonable.

Generally, all models showed that direct selection forces where the most dominant, as adding the $C_{k}$ term (Equation 2) did not seem to offer much improvement, which can be seen by looking at the DIC values of Table 3. One interpretation of this result is that the model does not capture selection that is mediated by interspecific interactions, nor the potential nonlinearity of the cover. However, the model overall assumes linearity $\left(q_{j}^{\prime}\right.$ times model terms), and a scatter plot of the covers in the two observed years revealed a linear tendency in the nonparametric Lowess-estimator with a strongly significant Pearson correlation $(R=0.78)$ ( see the upper left subplot of Figure 2$)$. However, if the models are suitable, their predictions should mimic that of the original data. The remaining subplots of Figure 2 show predictions against the independent variable $\left(q^{\prime}{ }_{j}\right)$ based on the mean parameter of the posterior MCMC-distributions. The header of the subplot identifies the different models.

Notice that the full model and the KM-selected model are plotted in the same subplot, as shown in the Figure 2 legend. When looking at the trend lines, and residual plots (Appendix A.4), Model 3 (directional selection) gives the best predictions. The $R^{2}$ ranges from -0.2 (model 5) to 0.77 (Model 3), showing that the best model gives $R^{2}$ similar to the original data. Though model 5 with variable selection gave lower $A A B$ and DIC, Model 3 seems to give the most reasonable predictions when looking at the subplot (Figure 2).

For all models, the variable selected models gave less variation in the output, though judging from the DIC and $A A B$, and were sometimes better than the full model (Table 3). However, when looking at the actual predictions, it became clear that in many cases this was due to reductions in variance (many 0 and 1 predictions) and not due to effective better models. Especially the near to 0 predictions can give high DIC values because the raw data contains many near to 0 observations. 
The predictive simulation using the Kolmogorow-Smirnow test is good supplement to the DIC and AAB, as the variation in prediction cover is tested against the observed cover. In Figure 3, boxplot of test-values confirms that Model 3 is the best model that includes selection that is mediated by interspecific interactions $\left(C_{k}\right.$ term, ) because it has the lowest test value. It can be seen that the simpler version of Model 3 (Model 1) excluding the $C_{k}$ term is the best according to the Kolmogorow-Smirnow test. This indicates that directional selection is important driver for species cover. Also, the grey boxplots show the same test results based on significant variable selected terms. There is a big difference between the original models and the variable selected models and, in most cases, it looks like the full models are better. Notice, however, that in all cases $p$-values obtained from the test were not significant (not shown), due to the sensitivity of the Kolmogorow-Smirnow test.

In Figure 4, the results of the variable selection procedure on the different $I_{k}$ terms of Equation 4 are shown. For each model we see the proportion of times that the MCMC procedure retains the trait value, to the total number of iterations excluding burn-ins. Thus if the bar has value 1 , the trait is always retained, indicating that it is an important predictor, and the closer to 0 the less important. We see that for all models except Model 5, vegetation height is important, whereas LDMC and SLA are often not retained and, in many cases close to not significant at the 5 percent level. The fact that traits perform differently for different models shows that the competitive process can be driven by different traits in different ways. The best model (Model 3), contrary to other models, ranked LDMC as important. However, if we consider model performance as a conclusive tool, then we must trust the model that performs the best according to $\mathrm{DIC}$ and $\mathrm{AAB}$. To this respect, the bars from Model 3 in Figure 4 is showing that all traits have some 277 importance, but that LDMC and SLA are most important, followed by vegetation height. It is interesting that 278 vegetation height for Model 3 seems slightly less important than for all other models. It shows that relying on a single model and not covering all three types of selection forces may lead to wrong conclusions. 
The Table 4 (lower half) showed the Pearson correlation coefficient between the parameters of Model 3. The t-test in the upper half shows that the parameters seem to be significantly correlated at the five percent level. The high correlations between parameters of the direct selection forces for the different traits indicate that they mimic the same property of plant performance.

The results are showing that hydrology seems important, since the parameters of the $H$ term $(H=$ $\left.a_{0 k+} a_{k} S E V\right)$ are significantly different from 0 . Interestingly, when looking at the parameter estimates and their range in Table 5, we see that the terms $a_{k F}$ and $a_{0 F k}$ are higher than their counterparts in the selection trait interaction term $\left(a_{k C}\right.$ and $\left.a_{0 C k}\right)$. This indicates that the direct trait selection seems to be a more important driver for selection forces over a hydrological gradient than selection that is mediated by interspecific interactions, and they have a combined impact on cover, which is in agreement with Damgaard et al. (2016). The signs of the slope of the $\mathrm{H}$ term $a_{k}$ indicate that vegetation height and SLA have a small positive impact on cover when including hydrology, whereas LDMC has a small negative impact. The less flooded the area becomes, the more important the direct selection forces are, which was also found by Merlin et al. (2015). But, as can be seen from Table 5, the 50th percentiles are close to 0 and results should not be over interpreted. When looking at the similar terms from $a_{c}$, we see that hydrology has a negative impact on the selection that is mediated by interspecific interactions for vegetation height and SLA and no impact for LDMC.

\section{Discussion}

The model presented here are in line with community based models where environmental variables sometimes latent affect the selection favoring certain characteristics of plants. Certainly the study of environmental variables such as the role of hydrology on succession is not new (Kikuzawa, 1991), and traits may enter categorical classification as done in the Ellenberg numbers and CSR databases along ecological gradients using statistical measures of correlation (Franzaring et al., 2007). The filter approach is a model based extension of these explorative methods, and tends explain the actual trait distribution by 
environmental/habitat filters that reduces the species pool followed by a limit to similarity filter. The latter ensures that each plant in the community have resources to live on, and no species becomes completely dominant (Garnier et al., 2016). Our approach is less subjective in estimation of the impact of traits on selection forces than a traditional filtering process, and does not require classification (numeric classes) as does for example the Ellenberg indicator. This is due to the simultaneous estimation, which "weights" the trait contributions to selection by means of parameters in the nonlinear models applied. As such, the method has some similarities with the much used structural equation modelling SEM (Weiher et al., 2011), since both account for contemporary correlations among the residuals/parameters of the models. The posterior parameter distribution may be applied to statistical inferences, and the correlation among parameters may be seen in a biological context. Furthermore, our method does not require any subjective definition of a null model. We cover all theoretical outcomes of selection a priori (see Table 2). This is, however, also a weakness because such assumptions cannot be proven correct in a mathematical sense, but only falsified by empirical testing (Chalmers, 1999) in the spirit of the philosopher Popper (Collin, 2003). However, if we believe that the models represent expressions for directional, disruptive and stabilizing selection, then we can say that one selection process explains data better, and most likely this conclusion is valid on a broader scale. One way to minimize the risk of misinterpretations is by means of a flexible model that can take many forms. Generalized additive models (GAM) (Wood, 2006) allow for flexible modelling of the selection forces and are an alternative to this approach that remain to be tested. Our model can be characterized as a classical nonlinear model (Seber and Wild, 2003), with an assumed stochastic error component (normal). It therefore fit into a broad range of community based ecological models, with a customized deterministic term (Bolker, 2008) in form of the nonlinear expressions of Table 2. In future applications incorporation of spatial information inside the pinpoint dataframe could be tested. A conditional autoregressive model (CAR) model is an obvious candidate for such a model and also works in the Baysian setting (Besag, 1974). 
As pointed out in the literature (Damgaard and Weiner, 2017; Harper, 1977), selection forces needs to be seen simultaneously in spatio-temporal scale, as competition pressure changes over time, as does the spatial pattern due to succession in the plant cover. The importance of considering spatial and temporal patterns is also evident when studying the literature on community growth as well as individual growth models (Schabenberger, 1994; Schabenberger and Pierce, 2002). We only have two temporal measurements, while a longer time-series is preferred. However, the data applied as model input includes plots of plant communities at similar stages of succession, and therefore the concern of looking at only two periods is minor. In addition, if needed, in future the model can be extended to having more than one measurement period. This can, for example, be done by assuming that the observed change in paired observations collected in different periods can be pooled and used to increase the number of observations. This allows us to apply the basic model in Equation 1, but requires an assumption that the temporal development does not have a trend, since the pairs applied as input comes from different time periods. This assumption may be reasonable in permanent grasslands dominated by perennial plant species ( $80 \%$ of the species), which exist for centuries and are not submitted to disturbances. In some cases, this assumption is less plausible, for example in areas with human disturbance. The studied marshlands are actually grazed every year and grazing cessation over several years may lead to substantial and directional temporal change (Marion et al. 2010). The data collection required the studied area to be fenced for two years, but this is probably too short a duration to affect species interaction, though it cannot be concluded that this is not the case. The fact that the area has been grazed prior to the experiment may influence the results. For example height as a proxy for species competitive ability becomes less prominent, as grazing tend to minimize the height contrast between species (Diaz et al 2007). Also, the selective browsing by horses and cows will favor some species over others (Marion et al. 2010, Saatkamp et al. (2010), with some species-specific response according to their tolerance ability. The traits themselves are probably selected 351 for or against. For example thornes' avoidance and preferred taste, as well as nutrient content may be 352 drive non-random consumption of plants' species by livestock and wild fauna (Milchunas and Noy-Meir, 
2002). In addition to browsing, livestock may spread nitrogen from excrements in a clustered way affecting nitrogen sensitive vegetation. In the positioning of the pinpoint frame, areas with visible excrements were avoided, to minimize such source of habitat heterogeneity.

If data allows for temporal classification, i.e. we can make a common point in time as reference start point of the plant community, then time $(t)$ can be added as a predictor (Equation 5 ). In addition, while our model additively includes several traits simultaneously, their covariance can be included in the future. This may e.g. be done by means of multiplication of two or more trait values, which can then enter the terms denoted $x$ and $y$ of Equation 5. The Bayesian approach allows for inclusion of many parameters even for small datasets, since the estimation procedure does not lose a degree of freedom such as a frequentist statistical estimation does. Due to running time of the MCMC, it may be advisable to make an initial reduction in the pool of traits available prior to MCMC.

\section{Equation 5}

$$
q_{j}^{\prime}=q_{j} \sum_{k=1}^{m}\left(F_{k}(x, S E V, t)\left(\sum_{y \in \Omega} C_{k}(x, y, S E V, t) q_{t_{k}=y}\right)\right)+\varepsilon
$$

The model architecture explicitly includes interspecific competition because it involves traits, but it ignores intraspecific competition. From a logical point of view, we cannot know if intraspecific competition will have an impact on the selection forces, and the model is therefore a simplification of reality. However, it has been recognized for long that the maintenance of species diversity in plant communities where the fundamental niches of several species overlap, required that interspecific competition to be less intense than the intraspecific competition (e.g. Chesson 2000). Thus, intraspecific competition is significant, and other models combining these two effect can be developed. Models involving intraspecific competition have often the weakness that the huge number of model parameters makes inference from the model difficult. This can be one justification to ignore this effect and broadly focus on the outcome of selection. 
Another argument is that trait contrasts are mainly expected to occur between species, which is then the main contrasts to focus on for predicting their effects along environmental gradients.

377

\section{Conclusion}

The model developed allows to investigate the importance of direct trait selection and selection that is mediated by interspecific interactions. It was tested using pin-point cover data from grasslands of the French Atlantic Coast. We tested 5 main models, in addition to 5 sub models, using variable selection. With reference to the objectives of the study, we conclude that:

a) All models can be fitted within reasonable time and are capable of using spatial as well as temporal effects. Many (in our case 3) trait values may be included, and their potential interaction can be modelled simultaneously and confounding statistical effects may be accounted for. The Bayesian approach allows for inferences to be made without assumptions of residual independence. The best model gave very similar predictions to the raw data, though some systematic residual patterns could be seen. Problems with observations of cover value 0 may have an impact on the model performance.

b) The direct selection forces seem to dominate in the current data, which can be seen from the model predictions, indicating that selection is driven towards a new mean optimum value.

c) Hydrology has an impact, most strongly in interaction with the direct trait selection forces and, to a minor extent, on the species interaction component. The forces of direct trait selection on the species cover are increasing with the reduction of the flooding duration/intensity.

The model can be extended to include one or more interaction terms among trait values, thus including covariance among traits in the model output.

\section{Acknowledgements}


398 The study was made as a part of the project "From vegetation patterns to ecological processes", supported 399 by The Danish Council for Independent Research. We are grateful to the Parc Naturel regional du Marais 400 poitevin and the Etablissement public du Marais poitevin for their support in maintaining the experimental 401 setting in the Magnils-Reigniers common (France). The authors thank the mairie des Magnils-Reigniers for 402 granting permission to work in the common.

403 404 
406

407

408

409

410

411

412

413

414

415

416

417

418

419

420

421

422

423

424

425

426

427

428

429

430

431

432

433

434

435

436

437

438

439

440

441

442

443

444

445

446

447

448

449

450

451

452

Adler, P.B., Fajardo, A., Kleinhesselink, A.R., Kraft, N.J.B., 2013. Trait-based tests of coexistence mechanisms. Ecology Letters 16, 1294-1306.

Amiaud, B., J-B., B., Tournade, F., Bonis, A., 1998. Spatial patterns of soil salinities and old embanked marshlands in western France. . Wetlands 18, 482-494.

Barbieri, M.M., Berger, J.O., 2004. Optimal Predictive Model Selection. The Annals of Statistics 32, 870-897.

Bernard-Verdier, M., Navas, M.-L., Vellend, M., Violle, C., Fayolle, A., Garnier, E., 2012. Community assembly along a soil depth gradient: contrasting patterns of plant trait convergence and divergence in a Mediterranean rangeland. Journal of Ecology 100, 1422-1433.

Besag, J.E., 1974. Spatial interaction and the statistical analysis of lattice systems Journal of the Royal Statistical Society Series B (Methodological) 36.

Bolker, B.M., 2008. Ecological Models and Data In R. Princeton University Press, Princeton.

Bolker, B.M., Pacala, S.W., 1999. Spatial Moment Equations for Plant Competition: Understanding Spatial Strategies and the Advantages of Short Dispersal. The American Naturalist 153, 575-602.

Chesson, P., 2000. Mechnanisms of maintenance of species diversity. Annual Review of Ecology and Systematics 31, 343-366.

Chalmers, A.F., 1999. What is this thing called science? Open University Press, Buckingham XXII, 266 s. pp. Climatedata.eu, 2017. Climatedata.eu, https://www.climatedata.eu.

Collin, F., 2003. Engelsk og amerikansk filosofi: videnskab og sprog. Politikens Forlag, København 599 s. pp.

Damgaard, C., 2016. Empirical modelling of trait selection by partitioning selection into direct selection and selection that is mediated by interspecific interactions. bioRxiv.

Damgaard, C., Merlin, A., Bonis, A., 2016. Plant colonization and survival along a hydrological gradient: demography and niche dynamics. Oecologia, 201-210.

Damgaard, C., Weiner, J., 2017. It's About Time: A Critique of Macroecological Inferences Concerning Plant Competition. Trends in Ecology \& Evolution 32, 86-87.

Diaz, S., Lavorel, S., McIntyre, S., Falczuk, V., Casanoves, F., Milchunas, D.G., Skarpes, C., Rusch, G., Sternberg, M., Noy-Meir, I., Landsberg, J., Zhang, W. Clark, H., Campbell, B.D. 2007. Plant trait responses to grazing- a global synthesis. Global Change Biol. 13, 313-341.

Dwyer, J.M., Laughlin, D.C., 2017. Selection on trait combinations along environmental gradients. Journal of Vegetation Science 28, 672-673.

Franzaring, J., Fangmeier, A., Hunt, R., 2007. On the consistencies between CSR plant strategies and Ellenberg ecological indicator values. Journal of Applied Botany and Food Quality 81, 86 - 94.

Garnier, E., Navas, M.-L., Grigules, k., 2016. Plant functional diversity. Organism traits, community structure and ecosystem properties. , 1 ed. Oxford University Press.

Gelman, A., Carlin, J.B., Stern, H.S., Rubin, D.B., 2004. Bayesian Data Analysis Second ed. Chapman \& Hall/CRC United States of America.

George, E.I., McCulloch, R.E., 1993. Variable Selection via Gibbs Sampling. Journal of the American Statistical Association 88, 881-889.

Gotelli, N.J., Graves, G.R., 1996. Null models in ecology. Smithsonian Institution Press United States of America.

Hara, T., 1984. Dynamics of stand structure in plant monocultures Journal of Theoretical Biology 110, 223239.

Harper, J.L., 1977. Population biology of plants. Academic Press, London.

Johnson, R.A., Wichern, D.W., 2007. Applied multivariate statistical analysis. Pearson Prentice Hall, Upper Saddle River, N.J. XVIII, 773 s. pp.

Loranger J, Violle C, Shipley B, Lavorel S, Bonis A, Cruz P, Louault F, Loucougaray G, Mesléard F, Yavercovski N, Garnier E. 2016. Recasting the dynamic equilibrium model through a functional lens: the interplay of trait-based community assembly and climate. J. Ecology 104 (3): 781-791 
Keddy, P.A., 1992. Assembly and response rules: two goals for predictive community ecology. Journal of Vegetation Science 3, 157-164.

Kikuzawa, K., 1991. A Cost-Benefit Analysis of Leaf Habit and Leaf Longevity of Trees and Their Geographical Pattern. The American Naturalist 138, 1250-1263.

Kuo, L., Mallick, B., 1998. Variable Selection for Regression Models. Sankhy\&\#x101;: The Indian Journal of Statistics, Series B (1960-2002) 60, 65-81.

Lavorel, S., Garnier, E., 2002. Predicting changes in community composition and ecosystem functioning from plant traits: revisiting the Holy Grail. Functional Ecology 16, 545-556.

Lortie, C.J., Brooker, R.W., Choler, P., Kikvidze, Z., Michalet, R., Pugnaire, F.I., Callaway, R.M., 2004. Rethinking plant community theory. Oikos 107, 433-438.

Massey, F.J., 1951. The Kolmogorov-Smirnov Test for Goodness of Fit. J. Am. St. Ass. 46, 68-78.

Mather, K., 1953. The genetical structure of populations in: Brown, R., Danielli, J.F. (Eds.), Symposia of the Society for Experimental Biology, pp. 66-95.

McGill, B.J., Brown, J.S., 2007. Evolutionary Game Theory and Adaptive Dynamics of Continuous Traits. Annual Review of Ecology, Evolution, and Systematics 38, 403-435.

Marion B., Bonis A. \& Bouzillé JB. 2010. How much grazing-induced heterogeneity impact plant diversity and richness in wet grasslands ? Ecoscience 17: 229-239.

Merlin, A., Bonis, A., Damgaard, C., Mesléard, F., 2015. Competition Is a Strong Driving Factor in Wetlands, Peaking during Drying Out Periods. PLoS ONE 10.

Milchunas, D.G., Noy-Meir, I., 2002. Grazing Refuges, External Avoidance of Herbivory and Plant Diversity. Oikos 99, 113-130.

Montgomery, D.C., Peck, E.A., Vining, G.G., 2006. Introduction to linear regression analysis., 4th ed. Wiley, Hoboken, New Jersey XVI, 612 s. pp.

Owen, J., Maillardet, R., Robinson, A., 2009. Scientific Programming and Simulation Using R. CRC Press, Taylor \& Francis Group, New York.

R Development Core Team, 2016. R: A language and environment for statistical computing, in: R Foundation for Statistical Computing (Ed.), Vienna, Austria.

Schabenberger, O., 1994. Nonlinear mixed effect growth models for repeated measures in ecology, Proceedings of the Section on Statistics and the Environment. Annual Joint Statistical Meetings Totonto, Canada

Schabenberger, O., Pierce, F.J., 2002. Contemporary statistical models for the plant and soil sciences. CRC Press, Boca Raton, Florida XXII, 738 s. pp.

Seber, G.A.F., Wild, C.J., 2003. Nonlinear regression. Wiley, Hoboken, New Jersey. Shipley, B., 2010. From plant traits to vegetation structure Cambridge, UK.

Spiegelhalter, D.J., Carlin, B.P., Van der Linde, A., 2002. Baysian measures of model complexity and fit (with discussion). journal of the Royal Statistical Society Series B (Methodological) 64, 583-639.

Swetnam, R.D., Mountford, J.O., Armstrong, A.C., Gowing, D.J.G., Brown, N.J., Manchester, S.J., Treweek, J.R., 1998. Spatial relationships between site hydrology and the occurrence of grassland of conservation importance: a risk assessment with GIS. Journal of Environmental Management 54, 189-203.

Saatkamp, A., Römermann, C., Dutoit, T., 2010. Plant Functional Traits Show Non-Linear Response to Grazing. Folia Geobotanica 45, 239-252.

Violle, C., Bonis, A., Plantegenest, M., Cudennec, C., Damgaard, C., Marion, B., Le Cœur, D., Bouzillé, J.-B., 2011. Plant functional traits capture species richness variations along a flooding gradient. Oikos 120, 389398.

Violle, C., Navas, M.-L., Vile, D., Kazakou, E., Fortunel, C., Hummel, I., Garnier, E., 2007. Let the concept of trait be functional! Oikos 116, 882-892.

Weiher, E., Freund, D., Bunton, T., Stefanski, A., Lee, T., Bentivenga, S., 2011. Advances, challenges and a developing synthesis of ecological community assembly theory. Philosophical Transactions of the Royal Society B: Biological Sciences 366, 2403-2413. 
502 Westoby, M., 1982. Frequency distributions of plant size during competitive growth of stands: the 503 operation of distribution-modifying functions. Ann. Bot. 50, 733-735.

504 Wood, S.N., 2006. Generalized additive models : an introduction with R. Chapman \& Hall/CRC, Boca Raton, 505 Florida. xvii, 392 s., ill. pp.

Wyszomirski, T., Weiner, J., 2009. Variation in Local Density Results in a Positive Correlation between Plant 507 Neighbor Sizes. The American Naturalist 173, 705-708.

508 Zuur, A.F., leno, E.N., Walker, N.J., Saveliev, A.A., Smith, G.M., 2009. Mixed Effects Models and Extensions 509 in Ecology with R Springer Science+Business Media, LLC New York, USA. 

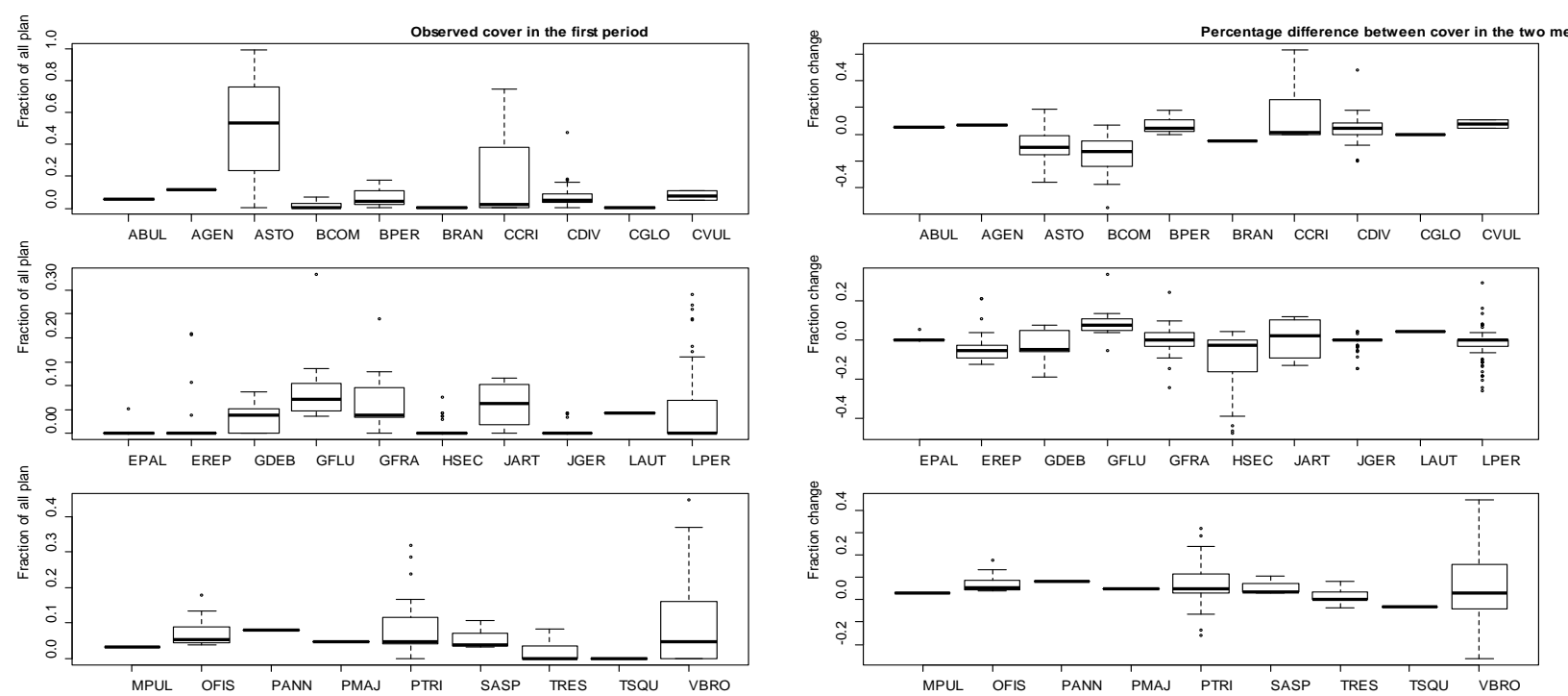

Species abbreviation

Figure 1. Histograms on the left side are showing the cover in percent for the different species in the first year of measurement. On the right side is the percentage change in cover between the two years of measurement for the same species. The abbreviation refers to the species abbreviation in Table 1. 

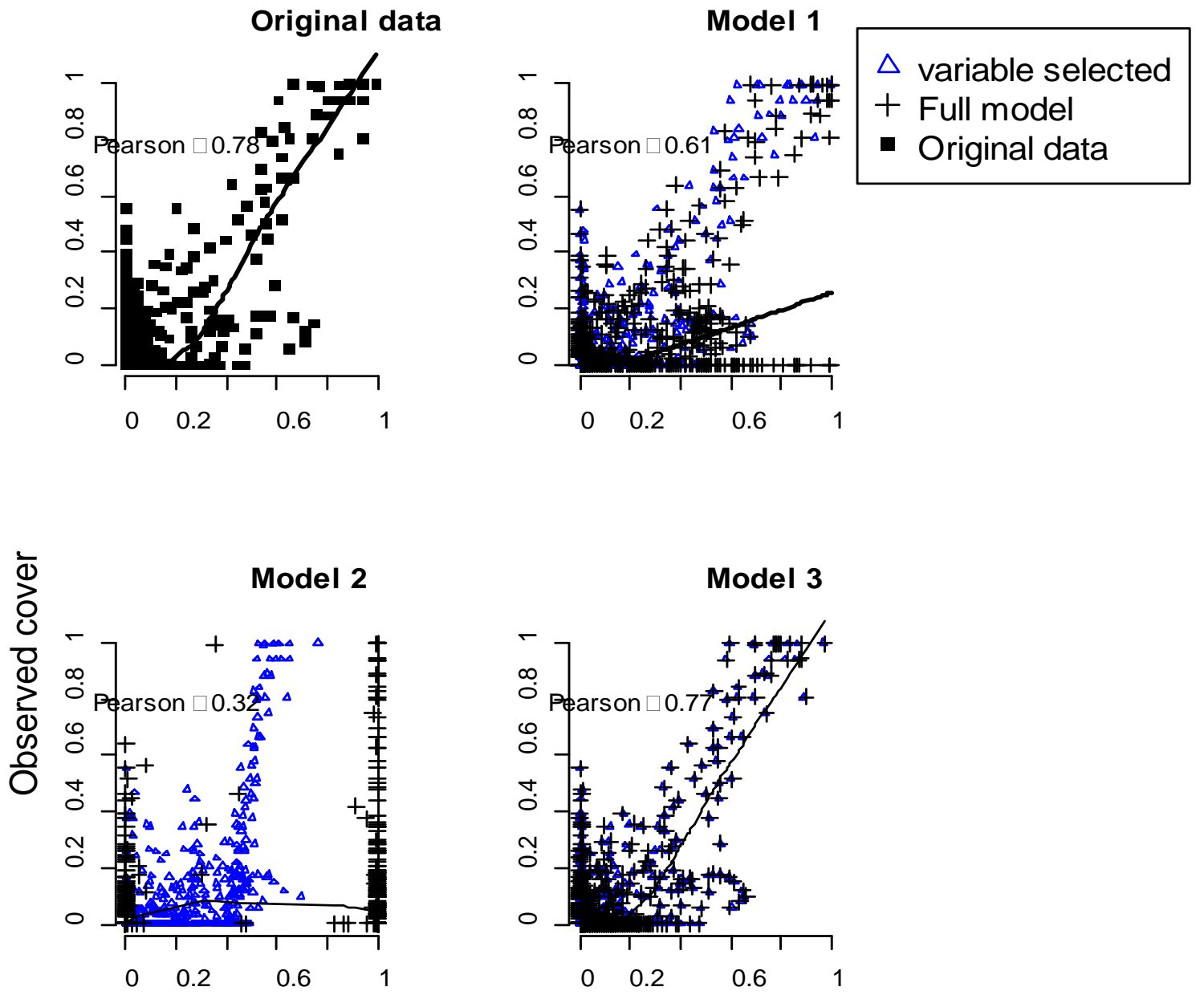

Model 4

Model 5
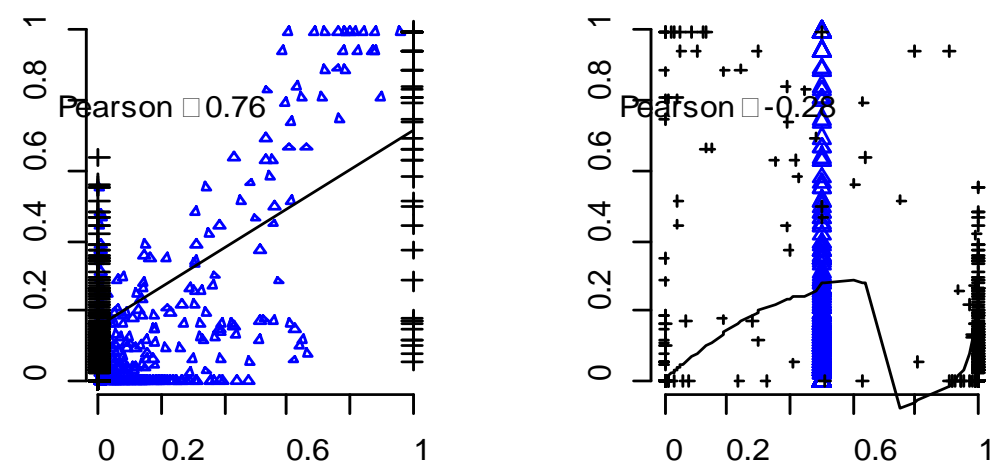

\section{Predicted cover}

Figure 2. Top left: The cover data entering the model as independent and dependent variable, with the against the predicted values using means of the multivariate parameter distributions from MCMC of the 

models.

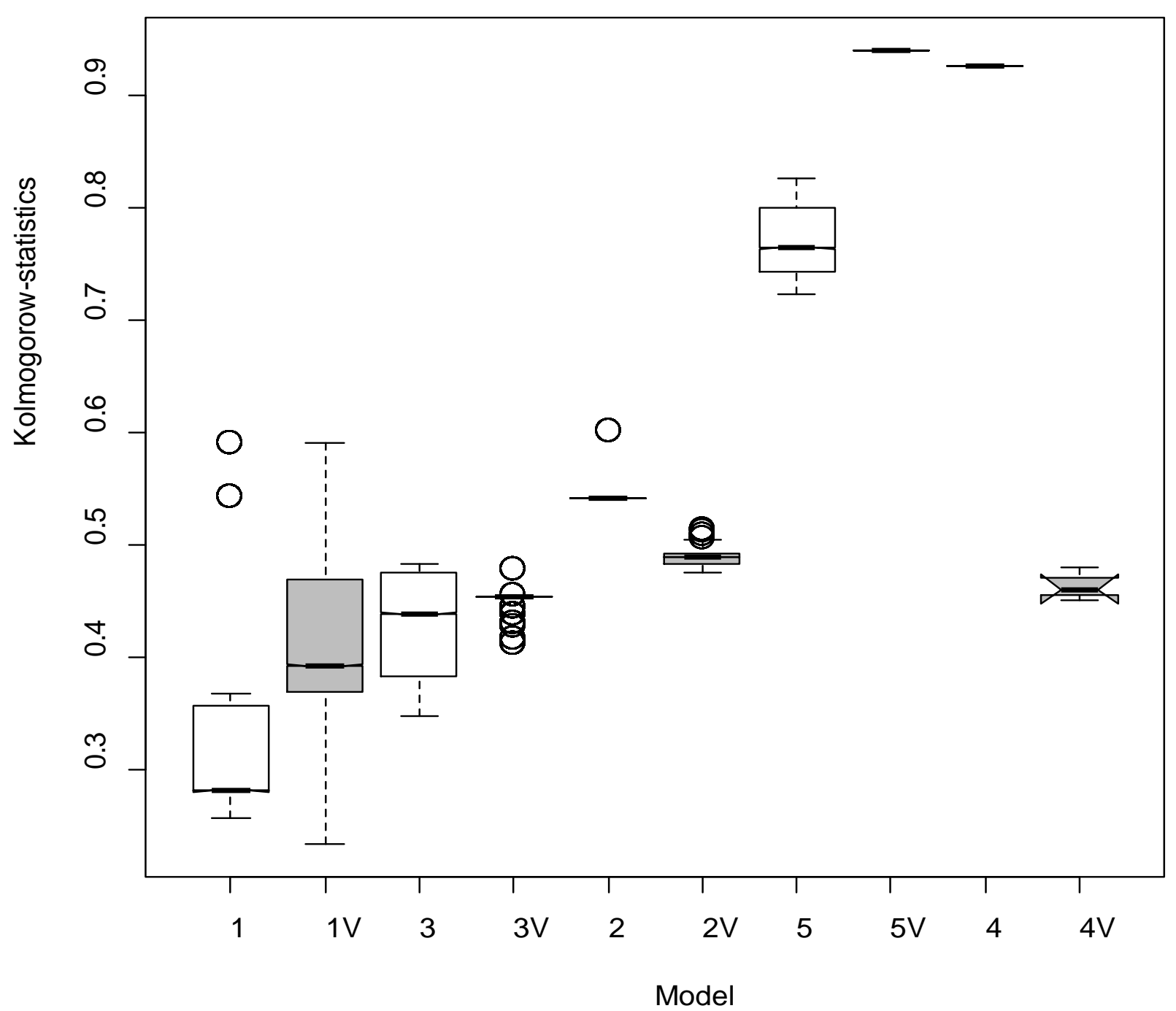

Figure 3. The test values of the Kolmogorow-Smirnow statistics when comparing the predicted cover distribution for each model with the observed empirical cover distribution. The full model is identified by its number and the variable selected model by the suffix " $V$ " (gray color). Model numbers refer to Table 2. 


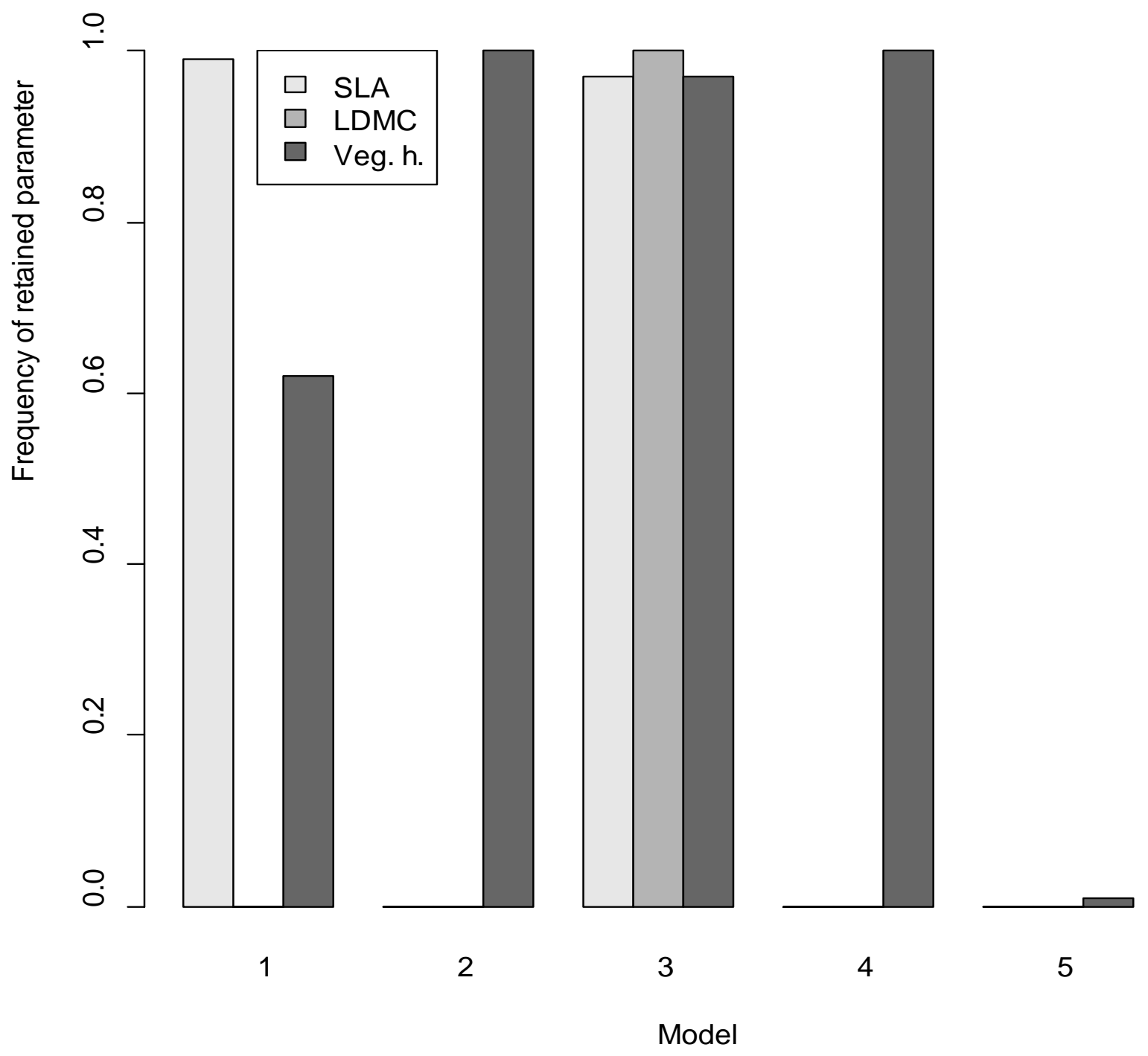

Figure 4. Barplot of the fraction of times that the indicator variable (trait) was included in the model (Equation 4), to the total number of MCMC iteration excluding burn-in. SLA, LDMC and Veg. $h$. (Vegetation height) shown in the legend, refers to the traits applied in the model. 
Table 1. The species trait values used in the study. Specific leaf area (SLA), Vegetative height (Veg. $h$ ),

\section{Species}

\begin{tabular}{lllll}
\hline Alopecurus bulbosus (Abul) & 28.6 & 0.28 & 215.1 & 0.06 \\
\hline Alopecurus geniculatus (Agen) & 27.55 & 0.3 & 211.95 & 0.13 \\
\hline Agrostis stolonifera (Asto) & 29.3 & 0.11 & 309.9 & 51.53 \\
\hline Bromus commutatus (Bcom) & 28.6 & 0.5 & 253.9 & 1.67 \\
\hline Bellis perennis (Bper) & 27.9 & 0.045 & 131 & 0.25 \\
\hline Baldellia ranunculoides (Bran) & 27.48 & 0.13 & 98.46 & 0.03 \\
\hline Cynosurus cristatus (Ccri) & 22.3 & 0.55 & 248.5 & 13.45 \\
\hline Carex divisa (Cdiv) & 13.5 & 0.49 & 230.2 & 3.84 \\
\hline Cerastium glomeratum (Cglo) & 35.07 & 0.15 & 576.3 & 0.00 \\
\hline Cirsium vulgare (Cvul) & 15.7 & 0.9 & 140.72 & 0.09 \\
\hline Eleocharis palustris (Epal) & 8.5 & 0.53 & 265.1 & 0.07 \\
\hline Elymus repens (Erep) & 21.5 & 0.75 & 301.2 & 1.67 \\
\hline Galium debile (Gdeb) & 39.6 & 0.21 & 197.7 & 0.85 \\
\hline Gaudinia fragilis (Gfra) & 31.28 & 0.28 & 235.35 & 1.73 \\
\hline Glyceria fluitans (Gflu) & 36.7 & 0.5 & 218.7 & 0.72 \\
\hline Hordeum secalinum (Hsec) & 29.3 & 0.33 & 269.1 & 6.90 \\
\hline Juncus articulatus (Jart) & 11.86 & 0.19 & 193.85 & 0.31 \\
\hline Juncus gerardi (Jger) & 10.2 & 0.33 & 256 & 1.04 \\
\hline Leontodon automnalis (Laut) & 25.91 & 0.07 & 157.74 & 0.03 \\
\hline Lolium perenne (Lper) & 26.7 & 0.13 & 227 & 7.15 \\
\hline Mentha pulegium (Mpul) & 33.9 & 0.17 & 136.5 & 0.03 \\
\hline Oenanthe fistulosa (Ofis) & 36.6 & 0.43 & 140 & 0.85 \\
\hline Poa annua (Pann) & 35.28 & 0.14 & 262 & 0.06 \\
\hline Plantago major (Pmaj) & 28.8 & 0.07 & $222.03^{1}$ & 0.03 \\
\hline Poa trivialis (Ptri) & 30.1 & 0.25 & 257.2 & 2.67 \\
\hline Sonchus asper (Sasp) & 24.7 & 0.18 & 123.67 & 0.16 \\
\hline Trifolium resupinatum (Tres) & 35.9 & 0.14 & 146.8 & 0.26 \\
\hline Trifolium squamosum (Tsqu) & 35.5 & 0.4 & 158.6 & 0.03 \\
\hline Vulpia bromoides (Vbro) & 30.5 & 0.1 & 254.4 & 4.37 \\
\hline & & & \\
\hline
\end{tabular}

$\begin{array}{llll}\mathrm{SLA}\left(\mathrm{m}^{2} / \mathrm{kg}\right) & \text { Veg. h. }(\mathrm{m}) \quad \text { LDMC }(\mathrm{mg} / \mathrm{g}) & \%\end{array}$ 
Table 2. The different kinds of selection models considered denoted by suffix $\boldsymbol{s}$ in the model. $\boldsymbol{F}$ is the function that capture selection forces due to the trait. $C$ is a function to model selection that is mediated by interspecific interactions for traits $x$ (subject) and $y$ (competitor) for the $k^{\prime}$ th trait. $H$ is the hydrology measure (SEV). $a_{0}, a, b_{0}, b, d, m$ and $z$ are model parameters, and their suffix (k) indicates the trait they are made for. DIR is directional selection, $S S$ is stabilizing selection, DIS is disruptive selection. Exp is the natural exponential.

\begin{tabular}{|c|c|c|c|c|c|}
\hline Model & explanation & Trait selection & Trait selection interaction & Hydrology & Explanation \\
\hline 1. & $\begin{array}{l}\text { Only subject trait, no } \\
\text { interaction } \\
\text { (directional selection) }\end{array}$ & $\begin{array}{l}F_{D I R_{-} k}(x, S E V) \\
=H b_{0 k} x+b_{k}\end{array}$ & None & $\begin{array}{l}H \\
=a_{0 k s+} a_{k S} S E V\end{array}$ & $\begin{array}{l}\text { Relative high or low trait values are } \\
\text { selected. }\end{array}$ \\
\hline 2. & $\begin{array}{l}\text { Only subject traits, no } \\
\text { interaction (stabilizing } \\
\text { selection) }\end{array}$ & $\begin{array}{l}F_{S S_{-} k}(S E V) \\
=H\left(x-z_{k}\right)^{2}+b_{k}\end{array}$ & None & $\begin{array}{l}H \\
=a_{0 k s+} a_{k s} S E V\end{array}$ & $\begin{array}{l}\text { Intermediate trait values will be } \\
\text { selected, reducing the variance } \\
\text { around the mean. }\end{array}$ \\
\hline 3. & Directional selection & $\begin{array}{l}F_{D I R_{-} k}(x, S E V) \\
=H b_{o} x+b_{k}\end{array}$ & $\begin{aligned} C_{D_{I R} k}(x, y, S E V) & \\
& =\operatorname{Exp}(-H(y \\
& -x)))\end{aligned}$ & $\begin{array}{l}H \\
=a_{0 k s+} a_{k s} S E V\end{array}$ & $\begin{array}{l}\text { Either high or low trait values are } \\
\text { selected. }\end{array}$ \\
\hline 4. & Stabilizing selection & $\begin{array}{l}F_{S S_{-} k}(x, S E V) \\
\left.=H\left(x-z_{k}\right)\right)^{2} \\
+b_{k}\end{array}$ & $\begin{array}{l}C_{S T_{\_} k}(x, y, S E V) \\
=\frac{\operatorname{Exp}\left(H\left(y-d_{k}\right)^{2}\right)}{\operatorname{Exp}\left(H\left(x-d_{k}\right)^{2}\right)}\end{array}$ & $\begin{array}{l}H \\
=a_{0 k s+} a_{k s} S E V\end{array}$ & $\begin{array}{l}\text { Intermediate trait values are selected. } \\
\text { The mean of the frequency will } \\
\text { remain unchanged, and the variance } \\
\text { will decrease }\end{array}$ \\
\hline 5. & Disruptive selection & $\begin{array}{l}F_{D I S_{-} k}(x, S E V) \\
=H\left(x-z_{k}\right)^{2}+b_{k}\end{array}$ & $\begin{array}{l}C_{D I S_{-} k}(x, y, S E V)=((1- \\
\left.\left.m_{k}\right) \frac{1-\operatorname{Exp}\left(H *\left(y-z_{k}\right)^{2}\right)}{\left.1-\operatorname{Exp}\left(H *\left(x-z_{k}\right)^{2}\right)\right)}+m_{k}\right)\end{array}$ & $\begin{array}{l}H \\
=a_{0 k s+} a_{k S} S E V\end{array}$ & $\begin{array}{l}\text { Extreme intermediate trait values are } \\
\text { seelcted. Change the trait frequency } \\
\text { from uni to bimodal }\end{array}$ \\
\hline
\end{tabular}


Table 3. The suffixes are DG= Direct growth, SS= Stabilizing selection, DIS= Disruptive selection. DIC = Deviance Information Criteria (smaller is better). $A A B=$ Average absolute bias. The model numbers refer to Table 2. In [] the best model including at least 1 of the terms for the three traits. In () the average model performance is given including all traits.

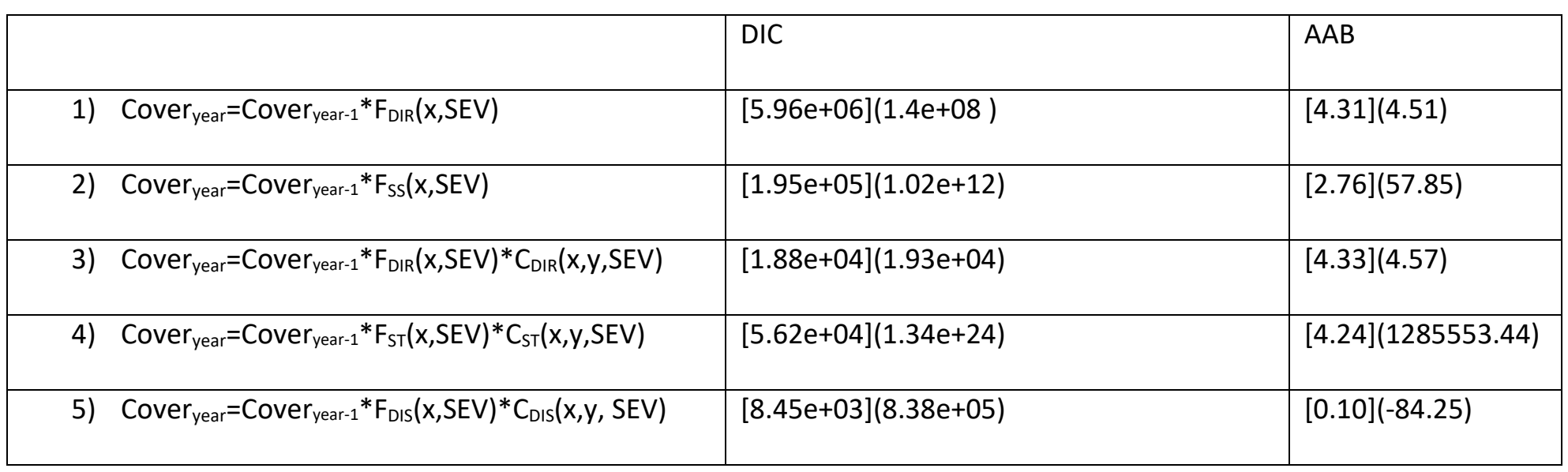


Table 4. In the lower half, the Pearson correlations between the parameters of the best performing model. In the upper half the p-value of a t-test

\begin{tabular}{|c|c|c|c|c|c|c|c|c|c|c|c|c|c|c|c|c|c|c|c|}
\hline & $a_{0 S L A}$ & $a_{0 F L D M C}$ & $a_{\text {ofvegh }}$ & $a_{F S L A}$ & $a_{F L D M C}$ & $a_{\text {Fveg }_{h}}$ & $b_{0 F S L A}$ & $b_{0 F L D M C}$ & $b_{0 \text { Fvegh }}$ & $b_{F S L A}$ & $\boldsymbol{b}_{\text {FLDMC }}$ & $b_{\text {Fvegh }}$ & $a_{0 C S L A}$ & $a_{0 C L D M C}$ & $a_{0 \text { Cvegh }}$ & $a_{\text {CSLA }}$ & $a_{C L D M C}$ & $a_{\text {Cvegh }}$ & $\sigma$ \\
\hline$a_{0 S L A}$ & 1.00 & 0.00 & 0.00 & 0.00 & 0.00 & 0.00 & 0.00 & 0.00 & 0.00 & 0.00 & 0.00 & 0.00 & 0.00 & 0.00 & 0.00 & 0.00 & 0.00 & 0.00 & 0.00 \\
\hline$a_{0 F L D M C}$ & -0.05 & 1.00 & 0.00 & 0.00 & 0.00 & 0.00 & 0.00 & 0.00 & 0.00 & 0.00 & 0.00 & 0.00 & 0.00 & 0.00 & 0.00 & 0.00 & 0.00 & 0.00 & 0.00 \\
\hline$a_{0 \text { Fvegh }}$ & -0.77 & 0.45 & 1.00 & 0.00 & 0.00 & 0.00 & 0.00 & 0.00 & 0.00 & 0.00 & 0.00 & 0.00 & 0.00 & 0.00 & 0.00 & 0.00 & 0.00 & 0.00 & 0.00 \\
\hline$a_{F S L A}$ & 0.58 & 0.44 & -0.50 & 1.00 & 0.00 & 0.00 & 0.00 & 0.00 & 0.00 & 0.00 & 0.00 & 0.00 & 0.00 & 0.00 & 0.00 & 0.00 & 0.00 & 0.00 & 0.00 \\
\hline$a_{F L D M C}$ & 0.28 & 0.47 & -0.22 & 0.66 & 1.00 & 0.00 & 0.00 & 0.00 & 0.00 & 0.00 & 0.00 & 0.00 & 0.00 & 0.00 & 0.00 & 0.00 & 0.00 & 0.00 & 0.00 \\
\hline$a_{\text {Fveg }_{h}}$ & 0.76 & 0.10 & -0.65 & 0.86 & 0.58 & 1.00 & 0.00 & 0.00 & 0.00 & 0.00 & 0.00 & 0.00 & 0.00 & 0.00 & 0.00 & 0.00 & 0.00 & 0.00 & 0.00 \\
\hline$b_{0 F S L A}$ & 0.21 & -0.25 & 0.15 & -0.51 & -0.57 & -0.23 & 1.00 & 0.00 & 0.00 & 0.00 & 0.00 & 0.00 & 0.00 & 0.00 & 0.00 & 0.00 & 0.00 & 0.00 & 0.00 \\
\hline$b_{0 F L D M C}$ & -0.57 & -0.09 & 0.69 & -0.87 & -0.31 & -0.77 & 0.47 & 1.00 & 0.00 & 0.00 & 0.00 & 0.00 & 0.00 & 0.00 & 0.00 & 0.00 & 0.00 & 0.00 & 0.00 \\
\hline$b_{0 F v e g h}$ & 0.70 & 0.29 & -0.63 & 0.97 & 0.60 & 0.92 & -0.39 & -0.90 & 1.00 & 0.00 & 0.00 & 0.00 & 0.00 & 0.00 & 0.00 & 0.00 & 0.00 & 0.00 & 0.00 \\
\hline$b_{F S L A}$ & 0.33 & 0.58 & -0.19 & 0.67 & 0.89 & 0.51 & -0.49 & -0.30 & 0.59 & 1.00 & 0.00 & 0.00 & 0.00 & 0.00 & 0.00 & 0.00 & 0.00 & 0.00 & 0.00 \\
\hline $\boldsymbol{b}_{F L D M C}$ & -0.58 & -0.60 & 0.36 & -0.95 & -0.78 & -0.82 & 0.43 & 0.71 & -0.92 & -0.78 & 1.00 & 0.00 & 0.00 & 0.00 & 0.00 & 0.00 & 0.00 & 0.00 & 0.00 \\
\hline $\boldsymbol{b}_{\text {Fvegh }}$ & -0.67 & -0.29 & 0.58 & -0.96 & -0.58 & -0.93 & 0.41 & 0.89 & -0.95 & -0.53 & 0.89 & 1.00 & 0.00 & 0.00 & 0.00 & 0.00 & 0.00 & 0.00 & 0.00 \\
\hline$a_{0 C S L A}$ & -0.59 & 0.32 & 0.88 & -0.49 & -0.46 & -0.56 & 0.42 & 0.57 & -0.58 & -0.46 & 0.41 & 0.49 & 1.00 & 0.00 & 0.00 & 0.00 & 0.00 & 0.00 & 0.00 \\
\hline$a_{0 \text { CLDMC }}$ & 0.68 & 0.36 & -0.40 & 0.81 & 0.70 & 0.88 & -0.15 & -0.57 & 0.80 & 0.59 & -0.85 & -0.87 & -0.30 & 1.00 & 0.00 & 0.00 & 0.00 & 0.00 & 0.00 \\
\hline$a_{0 \text { cvegh }}$ & 0.54 & -0.47 & -0.36 & -0.25 & -0.04 & 0.14 & 0.65 & 0.29 & -0.12 & -0.04 & 0.18 & 0.12 & -0.24 & 0.16 & 1.00 & 0.00 & 0.00 & 0.00 & 0.00 \\
\hline$a_{C S L A}$ & -0.27 & -0.11 & 0.36 & -0.70 & -0.06 & -0.60 & 0.36 & 0.87 & -0.70 & 0.03 & 0.51 & 0.75 & 0.14 & -0.46 & 0.49 & 1.00 & 0.00 & 0.00 & 0.00 \\
\hline$a_{C L D M C}$ & -0.83 & -0.01 & 0.49 & -0.50 & -0.22 & -0.73 & -0.30 & 0.45 & -0.56 & -0.12 & 0.50 & 0.67 & 0.20 & -0.79 & -0.50 & 0.38 & 1.00 & 0.00 & 0.00 \\
\hline$a_{\text {Cvegh }}$ & 0.68 & -0.09 & -0.61 & 0.71 & 0.22 & 0.89 & -0.04 & -0.80 & 0.81 & 0.09 & -0.60 & -0.84 & -0.36 & 0.73 & 0.08 & -0.79 & -0.77 & 1.00 & 0.00 \\
\hline$\sigma$ & 0.69 & -0.41 & -0.47 & 0.10 & -0.24 & 0.47 & 0.64 & -0.23 & 0.25 & -0.32 & -0.05 & -0.31 & -0.08 & 0.42 & 0.66 & -0.25 & -0.84 & 0.67 & 1.00 \\
\hline
\end{tabular}


561 Table 5. The quantiles of the parameters for Model 3 of Table 2, and the probability of the parameter 562 being larger than 0 . In [] the estimates from the variable selected model.

\begin{tabular}{|c|c|c|c|c|}
\hline Paramete & $2.5 \%$ & $50 \%$ & $97.5 \%$ & $P(X>0)$ \\
\hline \multicolumn{5}{|l|}{$a_{0 S L A}$} \\
\hline & 0.017 & 0.063 & 0.074 & 1 \\
\hline \multicolumn{5}{|l|}{$a_{0 F L D M C}$} \\
\hline & 0.03 & 0.037 & 0.069 & 1 \\
\hline \multicolumn{5}{|l|}{$a_{0 F v e g h}$} \\
\hline & -0.036 & -0.011 & 0.002 & 0.16 \\
\hline \multicolumn{5}{|l|}{$a_{F S L A}$} \\
\hline & -0.027 & -0.009 & 0.008 & 0.07 \\
\hline \multicolumn{5}{|l|}{$a_{F L D M C}$} \\
\hline & 0.001 & 0.001 & 0.002 & 0.99 \\
\hline \multicolumn{5}{|l|}{$a_{\text {Fveg }_{h}}$} \\
\hline & 0 & 0 & 0.001 & 1 \\
\hline \multicolumn{5}{|l|}{$b_{0 F S L A}$} \\
\hline & 0.009 & 0.009 & 0.009 & 1 \\
\hline \multicolumn{5}{|l|}{$b_{0 F L D M C}$} \\
\hline & 0.001 & 0.001 & 0.002 & 1 \\
\hline \multicolumn{5}{|l|}{$b_{\text {OFvegh }}$} \\
\hline & -0.006 & -0.006 & -0.002 & 0 \\
\hline \multicolumn{5}{|l|}{$b_{F S L A}$} \\
\hline & 0[] & 0.004 & 0.004 & 1 \\
\hline \multicolumn{5}{|l|}{$b_{F L D M C}$} \\
\hline & 0.003 & 0.005 & 0.005 & 1 \\
\hline \multicolumn{5}{|l|}{$\boldsymbol{b}_{\text {Fvegh }}$} \\
\hline & 0.003 & 0.004 & 0.004 & 1 \\
\hline \multicolumn{5}{|l|}{$a_{0 C S L A}$} \\
\hline & 0.006 & 0.009 & 0.009 & 1 \\
\hline \multicolumn{5}{|l|}{$a_{0 C L D M C}$} \\
\hline & -0.005 & -0.004 & 0.001 & 0.07 \\
\hline \multicolumn{5}{|l|}{$a_{0 \text { Cvegh }}$} \\
\hline & -0.002 & -0.001 & 0 & 0.02 \\
\hline \multicolumn{5}{|l|}{$a_{C S L A}$} \\
\hline & -0.001 & -0.001 & -0.001 & 0 \\
\hline \multicolumn{5}{|l|}{$a_{C L D M C}$} \\
\hline & 0 & 0 & 0 & 0.01 \\
\hline \multicolumn{5}{|l|}{$a_{\text {Cvegh }}$} \\
\hline & -0.001 & 0.001 & 0.001 & 0.72 \\
\hline \multicolumn{5}{|l|}{$\sigma$} \\
\hline & 1.004 & 1.012 & 1.012 & 1 \\
\hline
\end{tabular}


Master execution file: This file executes all programs for a specified model, using the below subprograms.

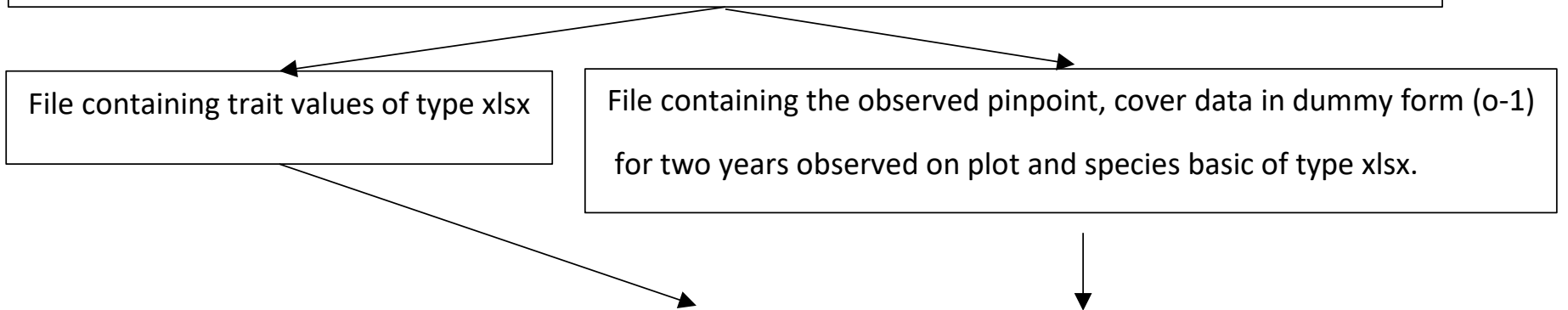

File likelihoodfunction5: Calculate the cover for each species on plot basis and make the Required imputations for missing data point.

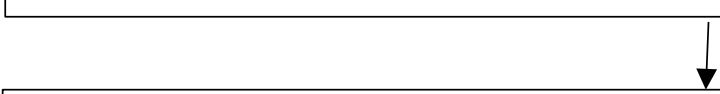

Model file 1-5: Performs the MCMC, parameters to be set are explained in the program.

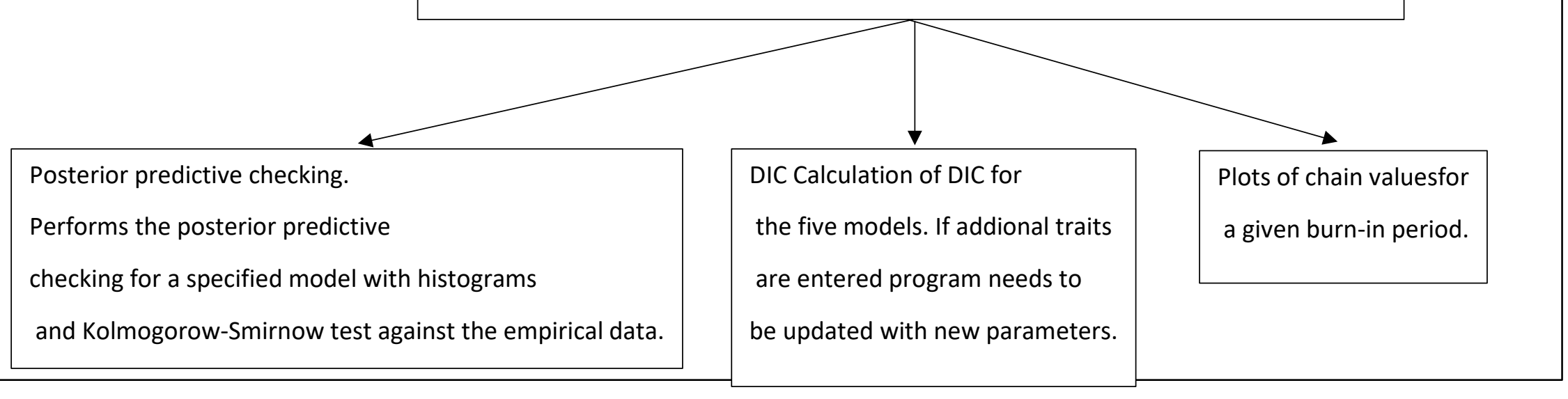




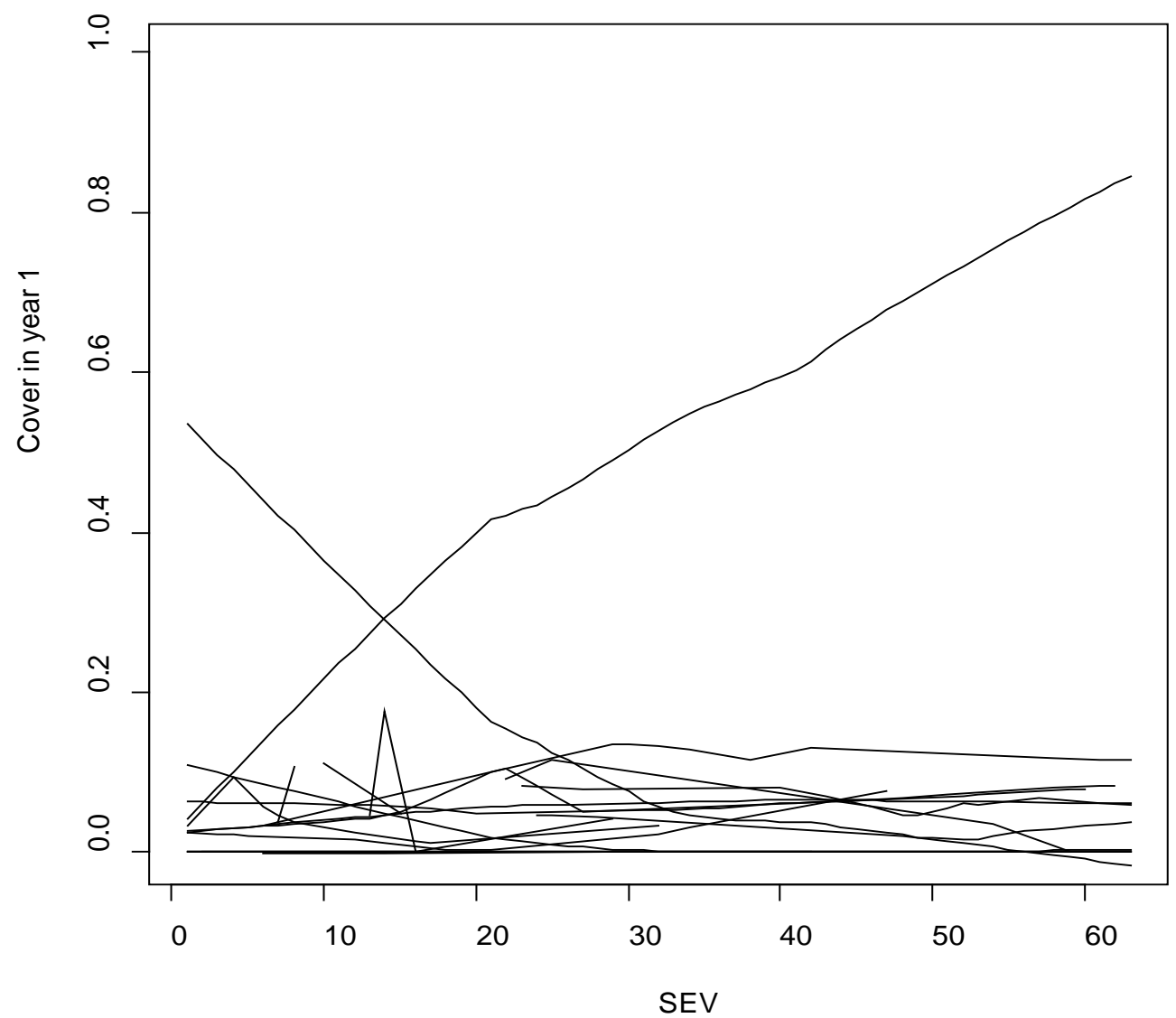




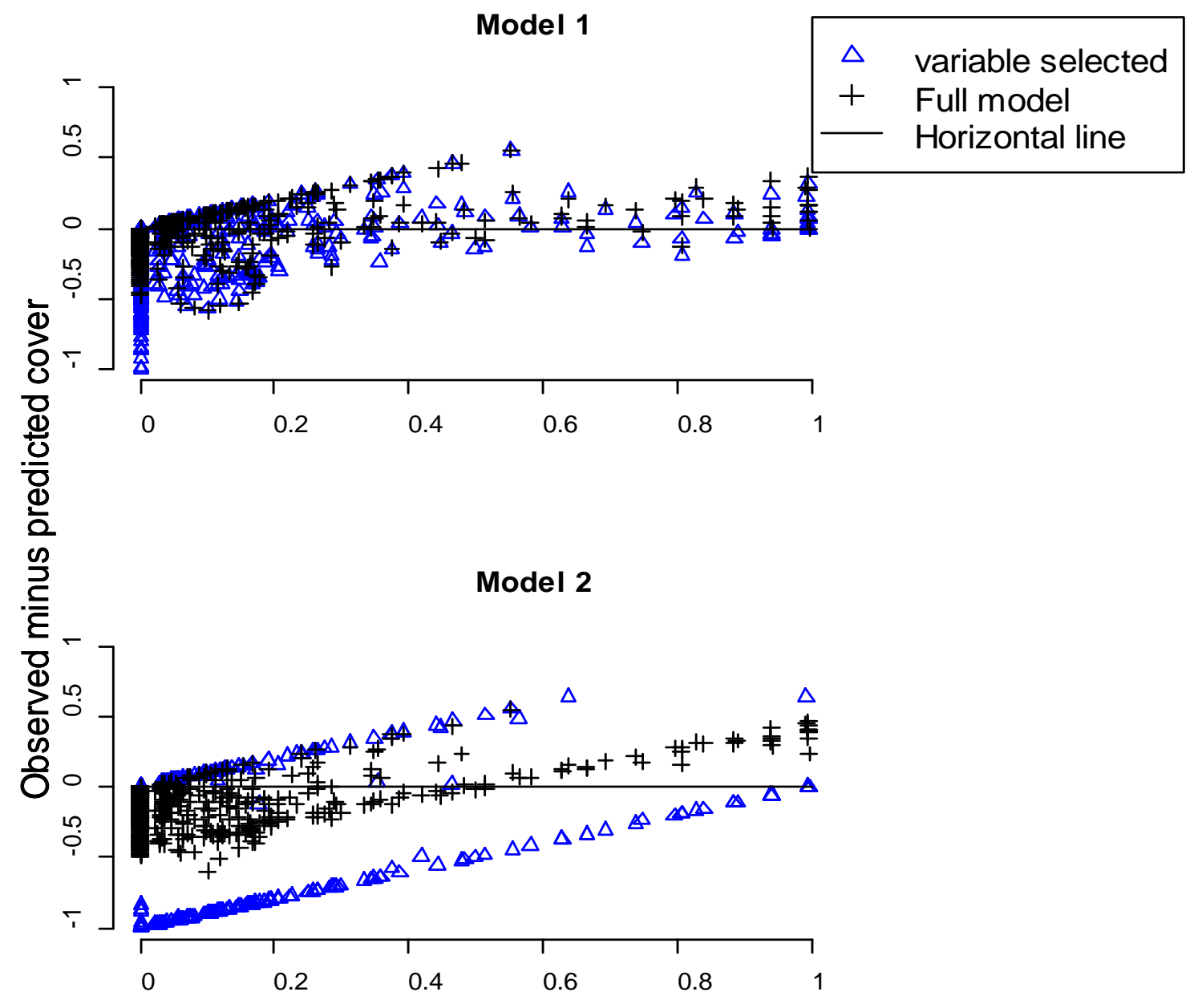

Model 3

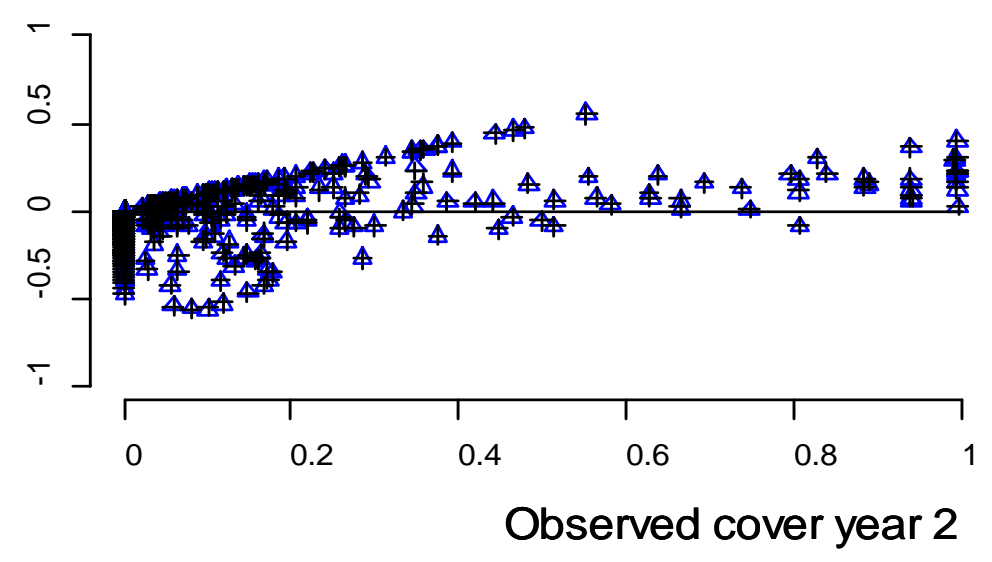


575 Figure A.3 1. Residual plots of the models shown in Table 2 identified by the title of the subplots. The 576 horizontal line is corresponding to a complete match between model observed cover. Continues in Figure 577 A.3 2.

578 Appendix A.4

579

580 


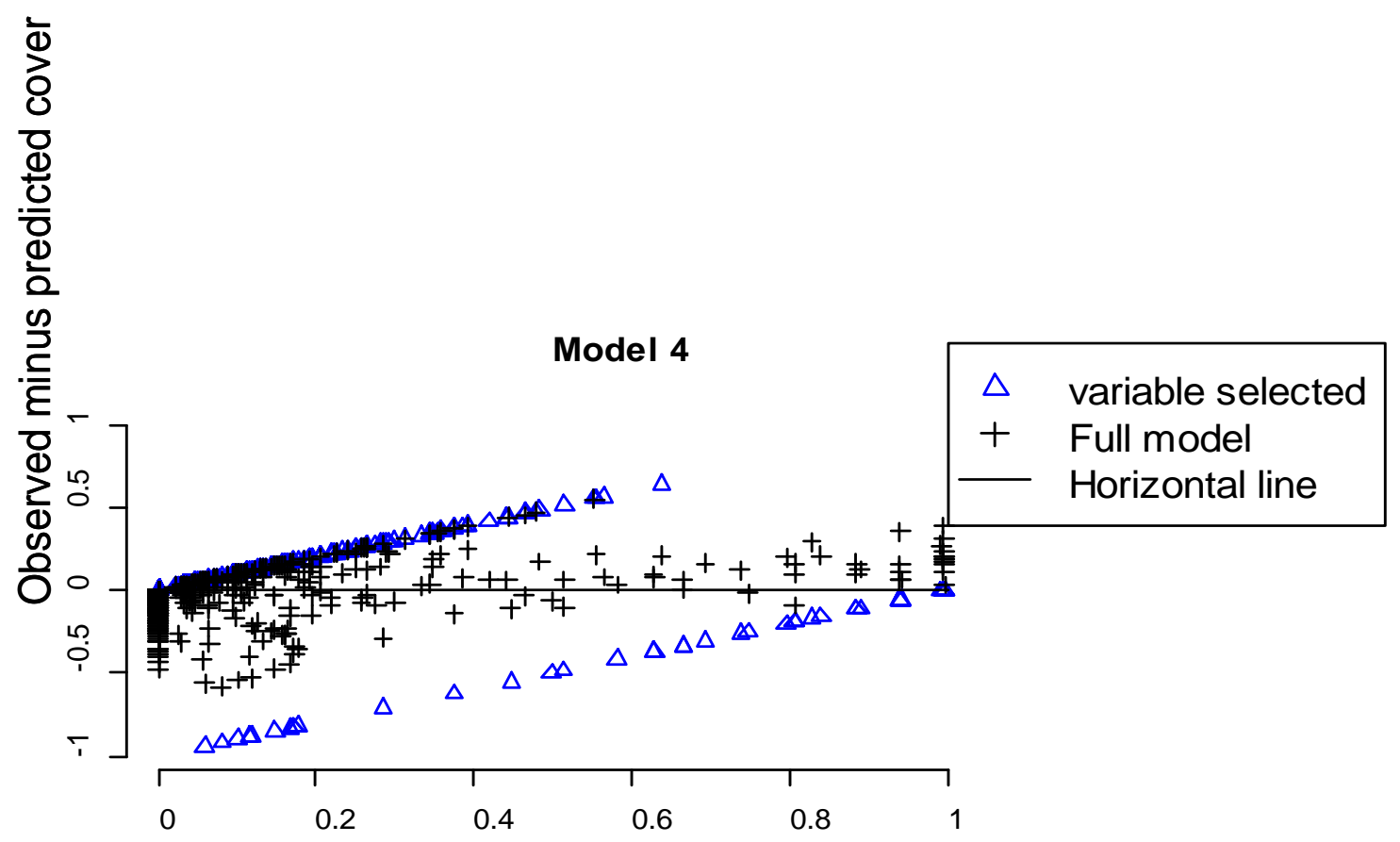

Model 5

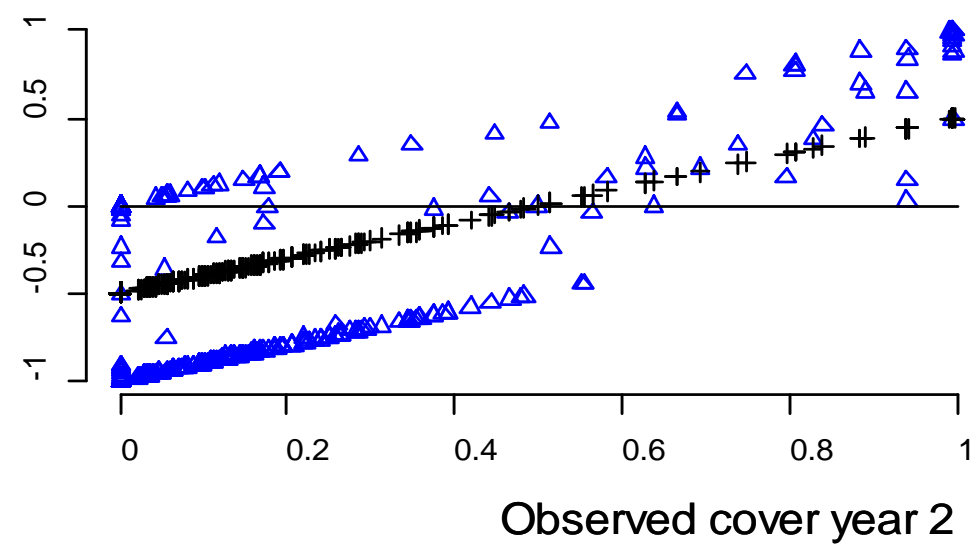


Figure A.3 2. Residual plots (continued from Figure A.3 1) of the models shown in Table 2 identified by 583 the title of the subplots. The horizontal line is corresponding to a complete match between model 584 observed cover. 